ПОКИДА Андрей Николаевич - кандидат социологических наук, директор Научноисследовательского центра социально-политического мониторинга Института общественных наук Российской академии народного хозяйства и государственной службы при Президенте РФ (119571, Россия, г. Москва, пр-кт Вернадского, 82; pokida@rambler.ru)

ЗЫБУНОВСКАЯ Наталья Владимировна - научный сотрудник Научно-исследовательского центра социально-политического мониторинга Института общественных наук Российской академии народного хозяйства и государственной службы при Президенте РФ (119571, Россия, г. Москва, nр-кт Вернадского, 82; nzyb@таil.ru)

\title{
ПРАВОВОЕ СОЗНАНИЕ САМОЗАНЯТЫХ ГРАЖДАН
}

\begin{abstract}
Аннотация. Статья основана на результатах социологических исследований, посвященных изучению правовой культуры различных социальных и профессиональных групп российского населения 1 . Особое внимание было сосредоточено на изучении правового сознания самостоятельно занятых граждан как категории работников, осуществляющих предпринимательскую деятельность исключительно на личном участии. Результаты исследования фиксируют довольно низкий уровень правосознания у самозанятых. Данная категория граждан, как и в целом представители малого предпринимательства, выражает склонность к сознательному нарушению действующего законодательства. Они более лояльно, чем другие группы работающих, относятся к неуплате налогов гражданами, чаще других склонны игнорировать официальное оформление занятости, тем самым выражая готовность работать в «теневой» среде. Такое положение дел может говорить о дисбалансе интересов малого предпринимательства, в т.ч. самозанятых граждан, и государства, а также о наличии признаков отсутствия адекватного правового регулирования данной деятельности.
\end{abstract}

Ключевые слова: неофициальная занятость, правовая культура, правовая информированность, правовое сознание, правовые ценности, правовое поведение, предпринимательская деятельность, рынок труда, самозанятые граждане

\section{Специфика самозанятости как социально-экономического явления}

Изменение экономической и социально-политической ситуации в стране вызвало к жизни ряд новых явлений в сфере занятости населения. К ним можно отнести самозанятость как разновидность нетрадиционной, нестандартной занятости, в основе которой лежит самоорганизация.

Отдельные формы самостоятельной занятости существовали в России и в дореформенный период (портные, няни, репетиторы). Однако в процессе перехода к рыночным отношениям состав, масштабы, характер занятости и ее роль в экономике резко изменились. Самостоятельная занятость достигла значительных масштабов, к ее услугам в той или иной мере прибегает большинство населения. Несмотря на то что данная экономическая деятельность часто осуществляется вне правового поля, в российском обществе сформировалось позитивное отношение к услугам, предоставляемым самозанятыми, в силу их ценовой привлекательности и, соответственно, востребованности у населения. Результаты социологических исследований показывают, что каждый второй гражданин является потребителем различных товаров, работ или услуг, предоставляемых самозанятыми неофициально [Покида 2016].

По различным экспертным оценкам, в качестве самозанятых трудятся от

1 Социологические исследования проведены Научно-исследовательским центром социальнополитического мониторинга ИОН РАНХиГС в 2016-2018 гг. Выборочная совокупность в каждом из исследований составила 1600 чел. в возрасте 18 лет и старше в 35 субъектах РФ. Выборка репрезентирует территориальное размещение населения, соотношение жителей разных типов поселений, социально-демографические и профессиональные группы людей. Опросы проведены методом личного формализованного интервью по месту жительства респондентов. 
13 до 22 млн чел. ${ }^{1}$ По сути, самостоятельная занятость становится самостоятельным сегментом рынка труда и оказывает заметное влияние на состояние занятости населения и социально-экономическую ситуацию в стране в целом.

Самозанятость как форма экономической активности представляет собой предпринимательскую деятельность, однако со своими особенностями. Она ведется физическими лицами самостоятельно, на свой страх и риск, с использованием собственной инициативы при принятии решений при условии использования своих собственных ресурсов, без регистрации в качестве индивидуального предпринимателя и использования труда наемных работников. «Самозанятость является промежуточным явлением, охватывающим категорию лиц, получающих доход вне рамок трудовых отношений, но, по сути, не является предпринимательской деятельностью, направленной на систематическое извлечение прибыли» [Костюк 2017: 204]. При этом самостоятельная занятость может использоваться не только в качестве единственного способа дохода, но и для дополнительного заработка во время, свободное от исполнения обязанностей по трудовому договору. Как уже было упомянуто, самозанятые оказывают услуги физическим лицам, как правило, в частном порядке, неофициально, не предоставляя отчетность в налоговые органы. По данным опроса, проведенного Центром в 2016 г., 64,5\% самозанятых граждан не оформляют официальные взаимоотношения с заказчиками [Покида, Зыбуновская 2017: 56].

Важно отметить, что в условиях современной экономической ситуации самозанятость часто носит вынужденный характер, являясь одним из способов выживания, альтернативой безработице [Орлова 2010; Воловская и др. 2018; Козырева 2015].

Минюст России предлагает рассматривать самозанятых как новую категорию субъектов малого предпринимательства и выделяет следующие критерии отнесения к самозанятым: это «физические лица, осуществляющие основанную исключительно на личном участии предпринимательскую деятельность по продаже произведенных такими лицами товаров, оказанию услуг, выполнению работ для физических лиц, в том числе во время, свободное от исполнения обязанностей по трудовому договору; не зарегистрированные в качестве индивидуальных предпринимателей; представившие уведомления об осуществлении указанной деятельности в налоговый орган в соответствии с законодательством Российской Федерации о налогах и сборах» 2 .

На текущий момент самозанятость воспринимается как «теневой» сегмент экономики России. Не случайно в своем послании Совету Федерации 2016 г. президент РФ В.В. Путин обозначил в качестве одного из важнейших вопросов легализацию и определение правового статуса самозанятых граждан ${ }^{3}$. В указе Президента РФ «О национальных целях и стратегических задачах развития Российской Федерации на период до 2024 года» одной из стратегических задач на ближайшие 6 лет является обеспечение благоприятных условий осуществле-

1 Власти добрались до самозанятых: как отобрать доходы у 20 миллионов россиян. - MKRU. 01.04.2018. Доступ: https://www.mk.ru/economics/2018/04/01/vlasti-dobralis-do-samozanyatykh-kak-otobrat-dokhody-u-20-millionov-rossiyan.html (проверено 10.12.2018).

2 Минюст России предлагает закрепить в законодательстве РФ правовой статус самозанятых граждан. - КонсультантПлюс. Доступ: http://www.consultant.ru/law/hotdocs/53836.html (проверено 10.12.2018).

3 Послание Президента РФ Совету Федерации. - Президент России. Официальный сайт. 01.12.2016. Доступ: http://kremlin.ru/events/president/news/53379 (проверено 05.12.2018). 
ния деятельности самозанятых граждан ${ }^{1}$. Регламентация деятельности самозанятых граждан необходима не только потому, что в данной сфере существуют весьма значительные денежные потоки, а в большей степени потому, что большая масса самостоятельно занятых физических лиц работает без возможности защиты своих трудовых прав и интересов.

Государство предпринимает меры по легализации деятельности самозанятых граждан, однако, судя по результатам, они пока не вполне эффективны. По официальным данным, к началу 2019 г. в качестве самозанятых зарегистрировались лишь 3 тыс. граждан ${ }^{2}$. Вместе с тем нужно отметить, что в развитии рынка самозанятости заключены колоссальные резервы, использование которых однозначно способствует развитию экономики страны с разных точек зрения: фискальной, увеличения занятости, развития микропредпринимательства, развития экономики и т.д.

С 1 января 2019 г. в 4 субъектах РФ (г. Москва, Московская обл., Республика Татарстан, Калужская обл.) стартовал эксперимент по легализации самозанятых, который предусматривает введение налога с доходов от реализации товаров, работ или услуг физическим лицам по ставке 4\%, индивидуальным предпринимателям, юридическим лицам $-6 \%$ и введение штрафных санкций ${ }^{3}$. При успешности данного эксперимента предполагается распространить его на все регионы страны.

Легализация деятельности самозанятых граждан в значительной степени сопряжена с их правовым сознанием, а именно с их знанием о действующих правовых нормах, с их отношением к закону и институтам государственного управления. Текущий уровень правосознания самозанятых во многом определяет их дальнейшее правомерное или противоправное экономическое поведение.

Результаты социологических исследований, проведенных авторами, позволили проанализировать особенности формирования правового сознания самостоятельно занятых граждан и его влияние на их участие в неофициальной экономической деятельности.

\section{Отношение самозанятых к правовым нормам}

Законопослушное поведение человека во многом зависит от уровня его правовой информированности, т.к. отсутствие правовых знаний зачастую может приводить к различным непреднамеренным нарушениям со стороны самих граждан, а также ограничивает их возможности по защите своих прав и интересов в случае их нарушения.

Проведенное исследование фиксирует невысокие знания самозанятых о действующих правовых нормах: только 26,0\% опрошенных самозанятых заявили, что хорошо знакомы с основными положениями Трудового кодекса РФ. Среди наемных работников $21,2 \%$ отметили этот факт, среди предпринимателей 42,6\%. Следовательно, самозанятые по своему уровню правовой информированности находятся скорее ближе к наемным работникам, чем к предпринимательскому сообществу. Несомненно, такой низкий уровень правовых знаний у

\footnotetext{
1 Указ Президента РФ от 07.05.2018 г. № 204 «О национальных целях и стратегических задачах развития Российской Федерации на период до 2024 года». - Президент России. Официальный сайт. Доступ: http://kremlin.ru/acts/bank/43027/page/1 (проверено 05.12.2018).

2 Статистика по самозанятым гражданам. - Федеральная налоговая служба. Доступ: https://www. nalog.ru/rn77/related_activities/statistics_and_analytics/selfemployed/ (проверено 21.01.2019).

3 Федеральный закон от 27.11.2018 N 422-Ф3 «О проведении эксперимента по установлению специального налогового режима "Налог на профессиональный доход" в городе федерального значения Москве, в Московской и Калужской областях, а также в Республике Татарстан (Татарстан)». Доступ: http://www.consultant.ru/document/cons_doc_LAW_311977/ (проверено 28.01.2019).
} 
самозанятых может выступать и выступает ограничительным фактором развития их потенциальной предпринимательской стратегии.

Кроме того, результаты опроса показывают, что большинство самозанятых $(60,4 \%)$ считают допустимым, когда граждане уклоняются от уплаты налогов при наличии такой возможности. В данном случае мнения самозанятых граждан в отношении практики неуплаты налогов отражают мнение всего предпринимательского сообщества, где устойчивым является позиция о несправедливости налоговой системы, отсутствии стабильности в законодательстве, коррупции в органах власти. Обман государства в некотором роде является компенсацией неблагоприятных условий ведения бизнеса, поэтому оправдывается предпринимателями. Не случайно сочувствие к практике уклонения от налогов у самозанятых граждан и предпринимателей выше, чем у наемных работников (см. рис. 1).

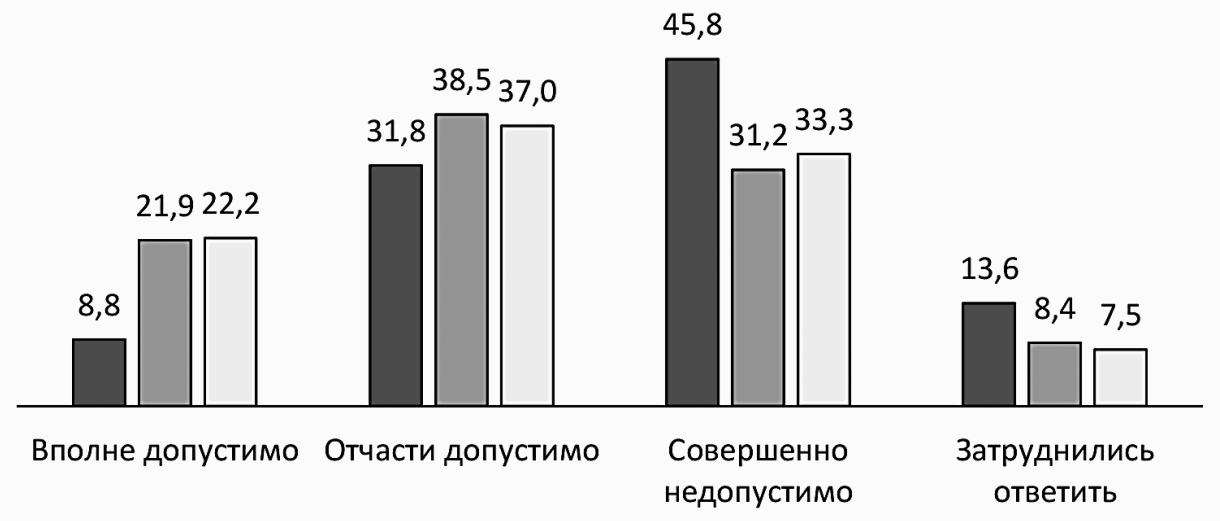

Занятые по найму $\square$ Самозанятые $\square$ Предприниматели

Рисунок 1. Отношение различных групп занятого населения к полному или частичному уклонению от уплаты налогов (в \% по каждой выделенной категории)

Результаты исследования показали, что самозанятые граждане в меньшей степени рассчитывают на законы с точки зрения возможностей защитить свои права. У них также ниже уверенность в необходимости соблюдения законодательства, в отличие от других групп занятых граждан. Они в большей степени считают, что если и нужно соблюдать действующее законодательство, то только при условии, что оно соблюдается представителями органов власти. К этому апеллирует каждый второй самозанятый. Среди наемных работников такой позиции придерживается только каждый третий респондент. Не случайно в качестве наиболее веского препятствия для законопослушного поведения граждан респонденты называют негативный пример правоохранительных органов и органов исполнительной власти. Среди самозанятых доля таких ответов составила $64,6 \%$.

В этой связи следует привести данные опроса 2016 г., демонстрирующие оценку респондентами налоговой политики в нашей стране, согласно которым значительная часть опрошенных самозанятых граждан $(59,7 \%)$ указала на ее несправедливость [Покида, Зыбуновская 2017: 57]. Стоит отметить, что оценка самозанятыми существующей налоговой политики более критична по сравнению с оценкой наемных работников, среди которых в несправедливости 
налоговой политики уверены 50,8\%. Тем не менее можно отметить, что среди различных групп занятого населения прослеживается недовольство текущей ситуацией в сфере налогообложения. Такое отношение работающего населения к существующей налоговой политике во многом объясняет значительные масштабы «теневой» экономики в стране.

\section{Отношение самозанятых к существующему правопорядку}

Как уже отмечалось выше, самозанятые граждане зачастую трудятся без официального оформления своей деятельности, поэтому на них не могут распространяться государственные социальные гарантии, в связи с чем для них сильно осложнена защита своих прав в случае их нарушения. Отсутствие юридических оснований обращаться в органы правопорядка не позволяет законным образом обезопасить себя, например, от риска несвоевременной оплаты от потребителя, риска неполучения оплаты за оказанные услуги или работы. Не чувствуют самозанятые достаточной защиты и от противоправных действий со стороны чиновников.

Так, по данным опроса, каждый пятый самозанятый сталкивался в течение 2017 г. с нарушениями своих прав органами государственной власти (при обращении в суд, полицию, рассмотрении трудовых конфликтов, оформлении пенсии, пособия, прав собственности или при предоставлении иных прав граждан). Для сравнения: на факты подобных нарушений указал каждый десятый наемный работник.

Такая негативная практика взаимодействия с институтами государственного управления отражается на оценках самозанятыми гражданами степени своей защищенности от возможного административного произвола властей. Почти треть самозанятых заявили о полном отсутствии какой-либо защиты от действий властей. Как следствие, все это отражается на уровне доверия самостоятельно занятых граждан к органам государственной власти (см. рис. 2), что в какой-то мере является препятствием легализации их профессиональной деятельности.

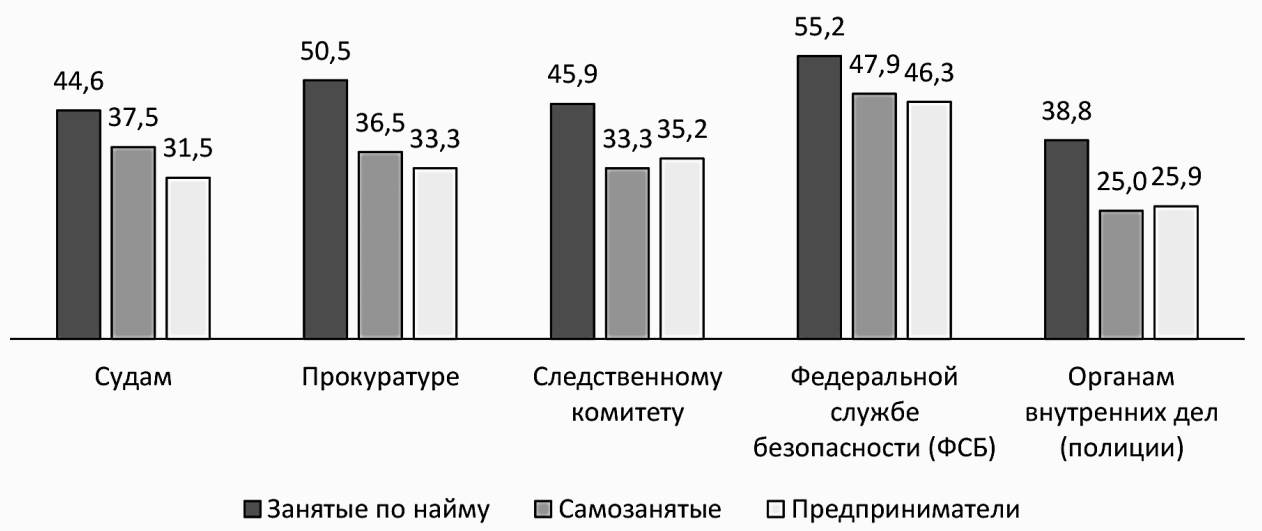

Рисунок 2. Уровень доверия органам правопорядка в различных группах занятого населения (в \% по каждой выделенной категории)

Следует отметить, что в целом в общественном мнении отмечается настороженное отношение к органам правопорядка, во многом связанное с распространенным среди граждан мнением о невозможности получить помощь при обращении к ним, о несправедливом и грубом отношении к гражданам, о без- 
законии и произволе представителей власти. Особенно много со стороны населения нареканий к деятельности полиции, с которой граждане контактируют более часто, чем с другими правоохранительными органами.

Что касается оценок нынешнего состояния правопорядка, то и здесь оценки самостоятельно занятых граждан не внушают оптимизма. Они в значительно большей степени, чем наемные работники, уверены, что в стране в настоящее время не утверждается верховенство закона, а усиливается административный произвол чиновников. В этом отношении с ними солидарны представители предпринимательского сообщества (см. рис. 3).

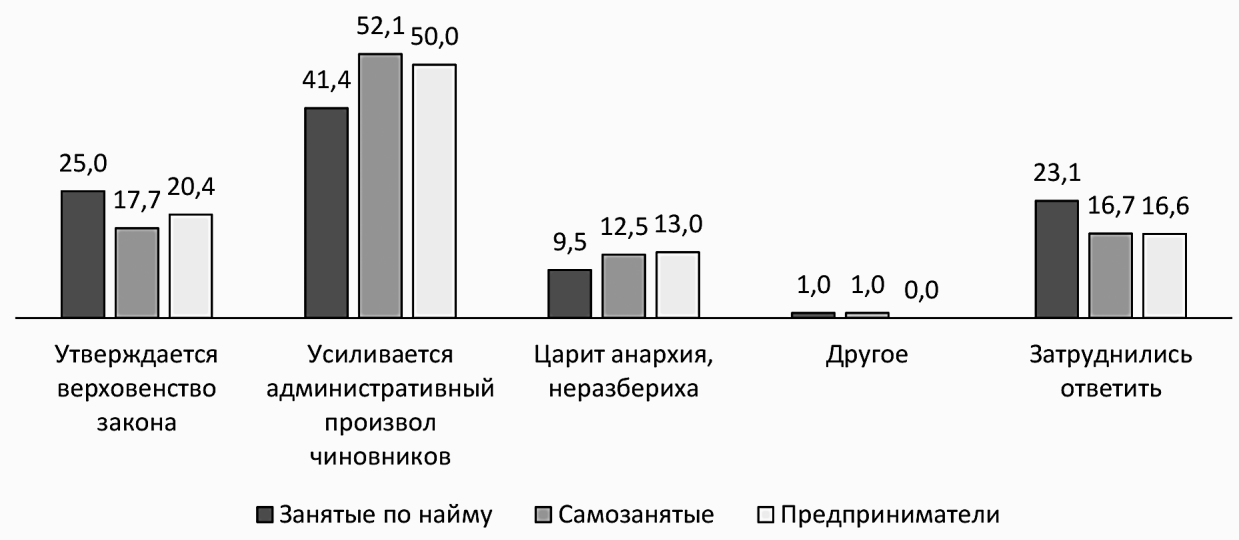

Рисунок 3. Оценка текущего состояния правопорядка в стране в различных группах занятого населения (в \% по каждой выделенной категории)

В этой связи реакция самозанятых на действия властей в повседневной жизни весьма прогнозируема. Согласно полученным данным опроса, поддерживают действия властей только 11,5\% самозанятых. Большая часть представителей данной группы либо вынуждены приспосабливаться $(33,3 \%)$, либо стараются держаться в стороне $(35,4 \%)$. Еще $9,4 \%$ самозанятых относятся к властям с неприязнью и по возможности противодействуют им.

При таком восприятии самозанятыми гражданами сложившейся ситуации в стране в плане реализации существующего законодательства в административно-бюрократических интересах отдельных групп легализация их деятельности сильно затруднена.

Резюмируя, следует отметить, что на современном рынке труда сформировалась новая категория субъектов малого предпринимательства - самозанятые граждане, деятельность которых регулируется законодательными нормами. По сути, самозанятые граждане - это те же индивидуальные предприниматели, однако их деятельность основана исключительно на личном участии по реализации товаров, работ или услуг физическим или юридическим лицам, без возможности использования наемных работников. Безусловно, законодательное закрепление правового статуса за самозанятыми гражданами позволит органам власти более активно проводить деятельность по их привлечению в официальную экономику, а самим самозанятым активнее развивать свою предпринимательскую инициативу.

Однако, исходя из вышеизложенного, можно предположить, что на пути «обеления» российской экономики, в т.ч. легализации самозанятых граждан, стоит довольно много препятствий, которые ставят под сомнение эффектив- 
ность предполагаемых органами власти мер по привлечению самозанятых в правовое поле. Результаты исследования показывают, что в настоящее время субъекты малого предпринимательства, а особенно самозанятые граждане, не стремятся к обладанию высоким уровнем правовой морали и к соответствующему правовому поведению. Данные категории граждан выражают склонность к сознательному нарушению действующего законодательства. Они более, чем другие группы, лояльны к различным проявлениям «теневой» экономической деятельности. Причины такого поведения кроются в невысоком уровне доверия указанных групп к институтам государственного управления, к существующему правовому порядку, регулирующему взаимоотношения граждан и государства.

Подобная ситуация может говорить о дисбалансе интересов малого предпринимательства и государства, а также о наличии признаков отсутствия адекватного правового регулирования предпринимательской деятельности.

В этой связи, во-первых, необходимо принять ряд мер по повышению доверия у граждан к органам власти, регулирующим правопорядок, а во-вторых, следует разработать действенные механизмы привлечения самозанятых граждан в официальную экономику, основанные не на запретительных или карательных мерах, а на создании благоприятных условий для их профессиональной деятельности.

\section{Список литературы}

Воловская Н.М., Плюснина Л.К., Русина А.В., Иноземцева А.В. 2018. Безработица и самозанятость: ожидания и реалии (по материалам социологических исследований). - Теория и практика общественного развития. № 11(129). C. 22-31.

Козырева П.М. 2015. Малое предпринимательство в России: повседневные проблемы и трудности развития. - Экономические и социальные перемены: факты, тенденции, прогноз. № 1(37). С. 43-58.

Костюк И.В. 2017. Занятость и самозанятость как форма доходной деятельности граждан. - Российский журнал правовых исследований. № 2(11). С. 202-206.

Орлова Л.В. 2010. Становление предпринимательства в российском обществе. - Вестник экономики, права и социологии. № 3. С. 182-185.

Покида А.Н. 2016. «Теневой» рынок труда: состояние, особенности формирования и перспективы. - Государственная служба. № 5(103). С. 12-17.

Покида А.Н., Зыбуновская Н.В. 2017. О тенденциях занятости работающего населения. - Социс. Социологические исследования. № 7. С. 54-59.

POKIDA Andrei Nikolaevich, Cand.Sci. (Soc.), Director of the Research Center for Social and Political Monitoring, School of Public Policy, Russian Presidential Academy of National Economy and Public Administration (RANEPA) (82 Vernadskogo Ave, Moscow, Russia, 119571; pokida@rambler.ru)

ZYBUNOVSKAYA Natal 'ya Vladimirovna, Research Fellow of the Research Center for Social and Political Monitoring, School of Public Policy, Russian Presidential Academy of National Economy and Public Administration (RANEPA) (82 Vernadskogo Ave, Moscow, Russia, 119571; nzyb@mail.ru)

\section{LEGAL CONSCIOUSNESS OF SELF-EMPLOYED CITIZENS}

Abstract. The article is based on the results of sociological research devoted to the study of the legal culture of various social and professional groups of the Russian population. The authors focus particular attention on the study of the legal consciousness of self-employed citizens as a category of workers engaged in entrepreneurial activities solely on personal participation. The results of the study fix a low level of legal consciousness among the self-employed. This category of citizens, as well as representatives of small business in general, expresses a tendency of violating the current legislation. 
They are more than other groups of workers loyal to tax evasion by citizens; more often tend to ignore the formalization of employment, thereby expressing readiness to work in the shadow environment. Such a state of affairs may indicate an imbalance in the interests of small businesses, including self-employed citizens, and the state, as well as the presence of signs of the lack of adequate legal regulation of this activity.

Keywords: informal employment, legal culture, legal awareness, legal values, legal behavior, entrepreneurship, labor market, self-employed citizens

БАРАНОВСКИЙ Максим Витальевич - кандидат социологических наук, докторант Военного университета Министерства обороны РФ (123001, Россия, г. Москва, ул. Большая Садовая, 14; m.baranovskj@gmail.com)

\section{СОВРЕМЕННЫЕ ПРАКТИКИ СОЦИОЛОГИЧЕСКОГО ИЗУЧЕНИЯ ФЕНОМЕНА ДОВЕРИЯ}

Аннотация. В статье предлагается обзор основных современных практик социологического исследования доверия. Автор приводит собственную классификацию доверия как социального явления по различным основаниям. На основе анализа тематики и содержания научных публикаций в известных социологических журналах, а также результатов исследований доверия, проведенных отечественными и зарубежными социологическими организациями, автор делает вывод о многообразии и разнородности подходов к изучению актуального социального феномена.

Ключевые слова: межличностное доверие, институциональное доверие, социальный институт, государственный институт, рейтинг

3 а последнее десятилетие масштабы изучения доверия социально-гуманитарными науками приобрели всеобъемлющий характер. Большой интерес исследователей к феномену доверия обусловлен его универсальностью и презентацией на всех уровнях социальной действительности.

Говоря об изучении доверия к основным социальным институтам общества, а также персонифицированного доверия к государственным руководителям, следует отметить, что большинство исследований проводятся не с целью всестороннего анализа социальной сущности и структуры доверия - на первый план выходят расчет индексов доверия, создание рейтингов социальных институтов и политических лидеров. Подобные исследования проводятся чаще не социологами-исследователями, а так называемыми полстерами. Однако деятельность ученых-социологов и полстеров отличается по своей цели и технологии ее реализации (см. табл. 1).

Сугубо прикладная, ориентированная на удовлетворение потребностей заказчика направленность таких исследований не всегда позволяет ответить на вопросы, что такое доверие и почему высокий уровень доверия позитивно влияет на общественное развитие. Каждый респондент понимает вопрос о доверии по-своему, о чем может свидетельствовать многообразие трактовок и классификаций социального явления даже в научной литературе.

Прежде чем приступать к проведению социологического исследования и измерению уровня доверия, необходимо определить, какой тип доверия подлежит измерению. Для этого целесообразно обозначить ряд подходов к его классификации. Выделяют следующие типообразующие основания: объект дове- 